Part of Journal of Research of the National Bureau of Standards, Volume 15, September 1935

\title{
PURIFICATION OF GALLIUM BY FRACTIONAL CRYSTALLIZATION OF THE METAL ${ }^{1}$
}

\author{
By James I. Hoffman and Bourdon F. Scribner
}

\begin{abstract}
It is shown in this paper that if gallium, containing (as impurities) small amounts of antimony, bismuth, chromium, cobalt, columbium, copper, gold, indium, iron, lead, manganese, mercury, molybdenum, nickel, osmium, palladium, platinum, rhodium, ruthenium, silver, thallium, tin, vanadium, and zinc, is subjected to fractional crystallization of the metal, all the impurities named tend to concentrate in the crystalline portion, with the following exceptions: Silver, mercury, indium, lead, and tin are concentrated in the molten residue; copper and thallium remain about equally divided between erystals and residue; zinc is dissolved by the hydrochloric acid under which the crystallization takes place, and is entirely eliminated.

It is also shown that separation from iron or platinum in excess of 0.001 percent, from indium or lead in excess of 0.01 percent, or from tin in excess of 0.02 percent by fractional crystallization of the metal is impracticable.
\end{abstract}

\section{CONTENTS}

I. Introduction -205

II. Preparation and crystallization of impure gallium 206

III. Approximate quantities of impurities that can be separated by fractional crystallization of the metal

IV. Discussion of results _...

\section{INTRODUCTION}

Fractional crystallization of the metal has been used in the purification of gallium by T. W. Richards and W. M. Craig ${ }^{2}$ and by one of the authors. ${ }^{3}$ Either by inference or by direct statement, the reader is led to believe that the crystals become purer and the residue less pure as recrystallization is continued. Thus, Richards and Craig state that they made use of the process of fractional crystallization of metallic gallium in order to eliminate any residual trace of other nonisomorphous metals, and in the work at this Bureau a similar process was used to eliminate the last traces of lead and indium. In both cases the crystals were found to be purer than the residue. In our recent work it was found, however, that platinum, iron, manganese, and certain other metals are collected in the crystals and practically eliminated from the uncrystallized portion. Consequently, it was deemed desirable to determine whether impurities, likely to be

1 The work described was done in connection with the purification of about $300 \mathrm{~g}$ of gallium for researches by Frederick J. Bates of the polarimetry section at the National Bureau of Standards.

'J. Am. Chem. Soc. 45, 1155 (1923).

3 James I. Hofiman, J. Research NBS 13, 665 (1934) RP734. 
present in gallium, tend to go into the crystals or into the residue during the process of fractional crystallization.

The fact that the crystals, obtained in our previous work and in that of Richards and Craig, were purer than the residue, shows that preliminary purifications had completely eliminated those elements which tend to collect in the crystals.

\section{PREPARATION AND CRYSTALLIZATION OF IMPURE GALLIUM}

In order to secure gallium containing such impurities as might be obtained by electrolysis of an alkaline solution, a portion of very impure metal was first prepared by electrodeposition ${ }^{4}$ from a 10 percent solution of sodium hydroxide to which had been added, usually as chlorides or sulphates, $10 \mathrm{~g}$ of pure gallium and $2 \mathrm{mg}$ each of antimony, arsenic, bismuth, cadmium, cerium, chromium, cobalt, columbium, copper, germanium, gold, indium, iridium, iron, lead, manganese, mercury, molybdenum, nickel, osmium, palladium, platinum, rhenium, rhodium, ruthenium, silver, tantalum, thallium, tin, tungsten, uranium, and vanadium. Any precipitate which formed was allowed to float in the solution during the electrolysis, to permit contamination by as many of the added elements as possible. Spectrochemical tests showed that the deposited gallium contained antimony, bismuth, chromium, cobalt, columbium, copper, gold, indium, iron, lead, manganese, mercury, molybdenum, nickel, osmium, palladium, platinum, rhodium, ruthenium, silver, thallium, tin, and vanadium. Although there is no assurance that any of the elements was quantitatively deposited, this gallium was so impure that crystallization of the metal was difficult. Consequently, two other portions of metal were prepared by mixing weighed amounts of this impure metal with pure metal in such proportions that the quantities of the elements contaminating the gallium were in the ratio $100: 10: 1$ in the 3 alloys.

Since none of these alloys contained iridium, rhenium, and zinc, a fourth $10-\mathrm{g}$ portion was prepared by electrolysis under the conditions previously stated, excepting that the alkaline electrolyte in this case contained only gallium and $5 \mathrm{mg}$ each of iridium and rhenium, and $10 \mathrm{mg}$ of zinc. Spectrochemical tests showed that only zinc and a very faint trace of rhenium were deposited with the gallium. It was observed during this work that usually only faint traces of cobalt, columbium, and rhenium were deposited.

These four 10-g portions of impure gallium were subjected to fractional crystallization as described by one of the authors. ${ }^{5}$ This process, as recommended for a 50-g portion of metal, is as follows:

To the gallium in a 50-ml beaker, add sufficient distilled water to cover the metal to a depth of about $0.5 \mathrm{~cm}$, warm to about $50^{\circ} \mathrm{C}$, and then add 5 to 10 drops of hydrochloric acid. Set the beaker in ice water, and, when the crystals appear, pick them out of the molten metal with the aid of glass-tipped tweezers. Continue picking out the crystals until only a small globule $(0.5$ to $1.0 \mathrm{~g})$ of metal remains. Combine and melt the crystals, and by the same process repeat the crystallization until crystals of the desired purity are obtained. Reserve the hydrochloric-acid solution and the small globules of uncrystallized metal for further purification. During the last crystallization, drop the

${ }_{4}^{4}$ The electrodes and current density were the same as were used in the preparation of pure gallium, J. Research NBS 13, 665 (1934) RP734.

s J. Research NBS 13, 669 (1934) RP734. 
crystals into cold alcohol and wash two or three times with alcohol by decantation. Dry the crystals by drawing clean dry air over them or by placing them in a desiccator over sulphuric acid. Preserve the crystallized metal in a stoppered flask.

Each portion of the impure gallium was fractionally recrystallized 10 times, about $0.5 \mathrm{~g}$ being allowed to remain uncrystallized every times. In this manner approximately equal amounts of crystals and uncrystallized residue were obtained from each original 10-g portion. The two portions, one consisting of the crystals and the other of the combined residues, were then melted separately in each case. Samples of the original and of these two portions were taken for spectrochemical analysis. These analyses showed that the elements deposited with the gallium are divided into the following classes when the impure metal is subjected to fractional crystallization:

1. Those that definitely tend to collect in the crystalline portion. These are antimony, bismuth, chromium, cobalt, columbium, gold, iron, manganese, molybdenum, nickel, osmium, palladium, platinum, rhodium, ruthenium, and vanadium. Traces of calcium and magnesium are often introduced by contact with containers or through dust. If present, these two elements likewise tend to concentrate in the crystalline portion.

2. Those that definitely tend to go into the residue. These are silver, mercury, indium, lead, and tin.

3 . Those that show little tendency to accumulate in either the crystals or the residue. These are copper, thallium, and zinc.

In the process used by us, the metal is crystallized under dilute hydrochloric acid. In 10 crystallizations, zinc is usually entirely dissolved by the acid so that it does not appear in the crystals or the residue. The amount of rhenium that it has been possible to deposit with the gallium has usually been so small that it is difficult to state definitely whether it would collect in the crystals or the residue.

The spectrochemical analyses were made by means of a stigmatic concave-grating spectrograph, ${ }^{6}$ and the spectra were examined for the sensitive lines of the elements involved.

\section{APPROXIMATE QUANTITIES OF IMPURITIES THAT CAN BE SEPARATED BY FRACTIONAL CRYSTALLI- ZATION OF THE METAL}

Since it is easily possible to recrystalize $100 \mathrm{~g}$ of gallium 25 times in 1 working day, fractional crystallization of the metal, without preliminary chemical purification, might seem to be a very efficient process for eliminating some of the impurities from the crude metal. It was noticed early in the work, however, that the process is not successful unless the amounts of impurities are very small.

Preliminary work showed that 35 recrystallizations of a portion of gallium containing 5 percent of indium and 0.03 percent of lead did not suffice to free the crystals from either indium or lead. Ten crystallizations, however, were sufficient to collect in the crystals practically all of 0.0003 percent of iron and all of the platinum that was introduced through attack of the electrodes during the deposition of gallium from a 10-percent solution of sodium hydroxide. One de-

'Described by W. F. Meggers, C. C. Kiess, and F. J. Stimson, BS Sci. Pap. 18, 244 (1922) S444; and by W. F. Meggers and Keivin Burns, BS Sci. Pap. 18, 191 (1922) S441. 
termination by chemical means indicated that platinum, so introduced, was not in excess of 0.001 percent.

In order to obtain further information on the elimination of small quantities of the impurities most frequently found in crude gallium, a $15-\mathrm{g}$ portion of the metal, to which was added 0.02 percent each of lead, tin, and indium, and 0.05 percent of zinc, was subjected to fractional crystallization. By means of 25 crystallizations the metal was separated into 2 equal parts, one consisting of crystals and the other of residue. Spectrochemical analysis of samples taken from these melted fractions showed that zinc was entirely eliminated from both the residue and the crystals, and all but a faint trace of tin was eliminated from the crystals. The amounts of indium and lead had decreased in the crystals, but the indications are that these would not have been eliminated, even if the number of recrystallizations had been doubled. The same number of crystallizations failed to eliminate all the indium and lead from a similar portion of gallium containing only 0.01 percent of each. In this case, however, the indium was reduced to a faint trace and the lead to such an extent that it seemed probable that it could have been eliminated if the number of recrystallizations had been doubled.

Judging by the results obtained, it can be said that it is impracticable to eliminate from the crystallized portion quantities of lead and indium in excess of 0.01 percent, or tin in excess of 0.02 percent by fractional crystallization of the metal. In the case of zinc, 0.05 percent can easily be eliminated, and the limit is probably somewhat higher. Traces of iron and platinum, but probably not much in excess of 0.001 percent in either case, can be eliminated by discarding the first portions of the crystals. Quantitative data on elements other than lead, indium, tin, zinc, iron, and platinum were not obtained, because those mentioned are the only metals that were found in the crude gallium examined by us.

\section{DISCUSSION OF RESULTS}

Gallium crystallizes in the tetragonal system. Of the metals in the impure gallium that was subjected to fractional crystallization, indium, thallium, and tin are the only ones that crystallize in the tetragonal system. ${ }^{7}$ The fact that so many of these elements are found in the crystallized portion cannot, therefore, be explained on the basis of isomorphism. The distribution of many of the other elements between the crystals and the residue could probably be explained by means of the constitutional diagrams if these were known. However, if the gallium is contaminated by an appreciable amount of metals of the platinum group, a slight scum may form on it. It is probable that this scum adheres to the crystals as they are removed from the molten metal, thus accounting for the presence of members of the platinum group in the crystallized portion.

The application of the information given above is not difficult. As a concrete example, consider a lot of metallic gallium which has been found by chemical or spectrochemical tests to contain less than 0.001 percent each of iron and platinum, less than 0.01 percent each of lead and indium, less than 0.02 percent of tin, and approximately 0.05 percent of zinc. In this instance, it would be practicable to

7 Int. Crit. Tạbles 1, 103-5 (1926) 
make 10 fractional crystallizations in such a manner that the final combined residues would constitute about nine-tenths of the total quantity taken. The platinum and the iron would probably be contained in the small crystalline portion, which would be set aside for purification by other means. The combined residues could then be subjected to the usual fractional crystallization, which would tend to eliminate the other impurities mentioned from the crystalline portion. It should be noted that purification by this process is practicable only if a considerable quantity (50 g or more) of gallium is available. It was also found that if dilute hydrochloric acid is allowed to react with a portion of impure gallium until about ninetenths of the metal is dissolved, practically all the lead remains in the undissolved portion.

Washington, July 12, 1935. 